\title{
CULTIVO DE MILHO NO SISTEMA DE ALÉIAS COM LEGUMINOSAS PERENES ${ }^{1}$
}

\author{
Maize crop in alley cropping system with perennials legumes
}

\author{
Luciano Rodrigues Queiroz², Fábio Cunha Coelho², Deborah Guerra Barroso²
}

\begin{abstract}
RESUMO
Objetivou-se avaliar a influência de algumas leguminosas perenes no teor foliar de N, P e K e na produtividade da cultura do milho (UENF 506-8), cultivado no sistema de aléias, sem adubação fosfatada. Foram realizados experimentos de campo por dois ciclos de cultivo, no Campo Experimental do CCTA/UENF, em Campos dos Goytacazes - RJ. Os tratamentos consistiram no sistema de aléias com Albizia lebbeck (L.) Benth., Peltophorum dubium (Spreng.) Taub., Leucaena leucocephala (Lam.) de Wit., Cajanus cajan (L.) Millsp., Sesbania virgata (Cav.) Pers., Mimosa caesalpiniaefolia Benth., Gliricidia sepium (Jacq.) Pers. e duas testemunhas com milho solteiro (com e sem NPK). Após oito meses de plantio das leguminosas, essas foram podadas, o material foi incorporado ao solo e em seguida semeado o milho nas entrelinhas, com espaçamento de $80 \mathrm{~cm}$ entre fileiras. Após 60 dias da semeadura do milho efetuou-se nova poda. No segundo ciclo de cultivo, as práticas culturais foram similares às do primeiro. Foi utilizado o delineamento em blocos casualizados com quatro repetições. Nas aléias de guandu, observou-se milho com maior teor foliar de $\mathrm{N}$, em relação às demais leguminosas, no primeiro ciclo de cultivo. No segundo ciclo, os consórcios milho+guandu, milho+gliricídia e milho solteiro adubado superaram os demais na produtividade de grãos.
\end{abstract}

Termos para indexação: Agroecologia, Consórcio, Fitomassa, Adubação Verde e Zea mays.

\section{ABSTRACT}

The objective of this study was to evaluate the effects of perennials legumes, in N, P and $\mathrm{K}$ foliar concentration and maize productivity in alley cropping system, without phosphorus fertilization. Field experiments were carried out for two cycles, with legumes intercropping maize (UENF 506-8) in Field Research CCTA/UENF in Campos dos Goytacazes - RJ - Brazil. The treatments consisted of alley cropping system with the species: Albizia lebbeck (L.) Benth., Peltophorum dubium (Spreng.) Taub., Leucaena leucocephala (Lam.) de Wit., Cajanus cajan (L.) Millsp., Sesbania virgata (Cav.) Pers., Mimosa caesalpiniaefolia Benth., Gliricidia sepium (Jacq.) Pers. and two control treatments: sole maize with or without fertilizer NPK. Eight months after the plantation, the legumes species were pruned and incorporated in soil. Maize was sown interows legumes, in rows spaced $80 \mathrm{~cm}$. New prune carried on sixty days after the first cut. In the second cycle, the crop handlings were similar to the first cycle. The experimental design consisted of randomized blocks with four replicates. In the alley cropping with Cajanus cajan the maize show the larger $\mathrm{N}$ foliar concentration, in first cycle. In the second cycle, maize+Gliricidia sepium, maize+Cajanus cajan and sole maize with NPK produced more grain than others treatments.

Index terms: Agroecology, Intercropping, Phytomass, Green Manure and Zea mays.

\section{(Recebido em 22 de setembro de 2006 e aprovado em 13 de março de 2007)}

\section{INTRODUÇÃO}

A cultura do milho está presente em todo o Estado do Rio de Janeiro, concentrando-se, principalmente, no Norte Fluminense. Os valores de rendimento médio de milho na região estão abaixo da média do país, refletindo a situação de subsistência da cultura e a utilização de sistemas de produção com baixos índices de tecnologia (CONAB, 2006). Agricultores familiares da região, de maneira geral, não possuem condições de adubar adequadamente suas culturas agrícolas. É comum observar plantas de milho com sintomas de deficiência nutricional, resultando em baixa produtividade.

Ultimamente, tem-se focado o estabelecimento de uma agricultura sustentável, fundamentada na manutenção da produtividade, na redução dos custos de produção e na preservação do ambiente. Assim, a utilização de processos microbiológicos, visando ao aumento da disponibilidade de nutrientes, torna-se necessária, especialmente com relação ao nitrogênio, cuja fixação biológica pode ser maximizada (STAMFORD et al., 1997).

O milho é uma cultura que remove grandes quantidades de $\mathrm{N}$ e, geralmente, requer adubação nitrogenada para completar a quantidade suprida pelo solo (COELHO et al., 2002). Nos países do Terceiro Mundo, o uso de adubação nitrogenada é limitado, pois, o pequeno produtor utiliza esse insumo agrícola de alto custo, somente quando o preço de seu produto é estimulador (RIBASKI et al., 2001).

\footnotetext{
${ }^{1}$ Extraído da Tese de Doutorado apresentada pelo primeiro autor (bolsista Faperj) ao Centro de Ciências e Tecnologias Agropecuárias da Universidade Estadual do Norte Fluminense Darcy Ribeiro/UENF - Avenida Alberto Lamego, 2000, Horto - 28013-602 - Campos dos Goytacazes, RJ. ${ }^{2}$ Doutores - Laboratório de Fitotecnia/LFIT - Universidade Estadual do Norte Fluminense Darcy Ribeiro/UENF - Avenida Alberto Lamego, 2000, Horto 28013-602 - Campos dos Goytacazes, RJ - lqueiroz@uenf.br; fcoelho@uenf.br, deborah@uenf.br
} 
A adubação verde é reconhecida como uma alternativa viável na busca da sustentabilidade dos solos agrícolas (ALCÂNTARA et al., 2000). Um dos sistemas em que se utiliza a adubação verde é o agroflorestal na forma de aléias, em que árvores e arbustos (leguminosas preferencialmente) são cultivados em fileiras, de forma intercalada com cultivos agrícolas (BARRETO \& FERNANDES, 2001). Dessa forma, os sistemas agroflorestais são considerados promissores por requererem menor uso de insumo externo que as monoculturas, por serem similares aos ecossistemas naturais (ALTIERI, 2002).

Heineman et al. (1997), avaliando no Quênia oito espécies de árvores leguminosas (Leucaena leucocephala, L. collinsii, Gliricidia sepium, Calliandra calothyrsus, Sesbania sesban, S. grandiflora, Senna siamea e $S$. spectabilis), obtiveram maior produtividade de milho na associação desta cultura com L. leucocephala e Gliricidia sepium. O rendimento de grãos foi positivamente correlacionado à quantidade de folhas aplicadas no solo.

Uma vez que, o cultivo de milho é bastante exigente em termos de fertilidade de solo, o uso de leguminosas arbóreas e arbustivas poderá ser uma alternativa eficiente e ao alcance dos pequenos agricultores para aumentar sua produtividade, na região Norte Fluminense.

Objetivou-se neste trabalho, avaliar a influência de algumas espécies de leguminosas perenes no teor foliar de N, P e K e na produtividade da cultura do milho, sem adubação fosfatada, no sistema de aléias, em Campos dos Goytacazes-RJ.

\section{MATERIAL E MÉTODOS}

Foram conduzidos experimentos com leguminosas arbóreas e arbustivas consorciadas com a cultura do milho, no sistema de aléias, no Campo Experimental do Centro de Ciências e Tecnologias Agropecuárias/Universidade
Estadual do Norte Fluminense (CCTA/UENF), em Campos dos Goytacazes-RJ (21 ${ }^{\circ} 45^{\prime}$ S, $41^{\circ} 18^{\prime}$ 'W e altitude média de $11 \mathrm{~m})$. O solo em que se realizou o ensaio é um Latossolo Amarelo Distrófico, e os resultados das análises química e textural estão no Quadro 1. O preparo do solo foi realizado com arado de discos e uma gradagem e, em seguida, feita a sulcagem para o plantio das leguminosas.

O experimento foi constituído por nove tratamentos, cada um correspondendo a uma espécie de leguminosa em aléia com o milho e duas testemunhas sem leguminosas: milho solteiro com e sem fertilizante mineral (+NPK e sem NPK). As espécies utilizadas foram: Albizia lebbeck (L.) Benth. (albízia), Peltophorum dubium (Spreng.) Taub. (canafístula), Leucaena leucocephala (Lam.) de Wit. (leucena), Cajanus cajan (L.) Millsp. (guandu), Sesbania virgata (Cav.) Pers. (sesbânia), Mimosa caesalpiniaefolia Benth. (sabiá ou sansão do campo) obtidas na UENF e estacas de Gliricidia sepium (Jacq.) Pers. (gliricídia) na UFRRJ em Seropédica-RJ.

Cada parcela foi constituída por uma fileira de cinco metros de comprimento, com duas plantas de leguminosa por metro linear. Em cada lado da fileira de leguminosa, foram semeadas três linhas de milho, espaçadas entre si em 0,8 m. Considerou-se como área útil, as duas linhas de milho adjacentes às leguminosas, num total de quatro linhas, descartados 0,5 $\mathrm{m}$ das suas extremidades.

Uma das testemunhas foi adubada de acordo com a análise de solo, conforme as recomendações regionais para a cultura do milho (POLLI, 1988), empregando-se 60 $\mathrm{kg} \mathrm{ha}^{-1}$ de $\mathrm{P}_{2} \mathrm{O}_{5}$ (superfosfato simples), $40 \mathrm{~kg} \mathrm{ha}^{-1}$ de $\mathrm{K}_{2} \mathrm{O}$ (cloreto de potássio) no plantio e $60 \mathrm{~kg} \mathrm{ha}^{-1}$ de $\mathrm{N}$ (uréia), sendo $1 / 3$ no plantio e o restante em cobertura, 30 dias após a emergência. A outra testemunha não recebeu adubação. As parcelas experimentais com podas de leguminosas não receberam nenhuma adubação mineral e o solo de experimento não foi corrigido com calcário.

QUADRO 1 - Análise química e textural do solo antes da instalação do experimento.

\begin{tabular}{|c|c|c|c|c|c|c|c|c|c|c|c|c|}
\hline pH & $\mathbf{P}$ & $\mathbf{K}$ & $\mathrm{Na}$ & $\mathbf{C a}$ & Mg & $\mathbf{H}+\mathbf{A l}$ & $\mathbf{C}$ & MO & S.B. & $\mathbf{T}$ & $\mathbf{m}$ & $\mathbf{V}$ \\
\hline & $\mathrm{mg} / \mathrm{dm}^{3}$ & \multicolumn{5}{|c|}{$\mathrm{cmol}_{\mathrm{c}} / \mathrm{dm}^{3}$} & $\%$ & $\mathrm{~g} / \mathrm{dm}^{3}$ & \multicolumn{2}{|c|}{$\mathrm{cmol}_{\mathrm{c}} / \mathrm{dm}^{3}$} & \multicolumn{2}{|c|}{$\%$} \\
\hline 5,5 & 6 & 38 & 0,04 & 2,0 & 1,3 & 4,3 & 1,17 & 20,2 & 3,4 & 7,7 & 3 & 44 \\
\hline \multicolumn{3}{|c|}{ Areia \% } & \multicolumn{3}{|c|}{ Silte \% } & \multicolumn{3}{|c|}{ Argila \% } & \multicolumn{4}{|c|}{ Classe textural } \\
\hline \multicolumn{3}{|c|}{52} & \multicolumn{3}{|c|}{9} & \multicolumn{3}{|c|}{39} & \multicolumn{4}{|c|}{ Argilo arenoso } \\
\hline
\end{tabular}

V = saturação de bases; S.B.= Soma de bases; $\mathrm{T}=$ CTC a pH 7,0; $\mathrm{m}=$ saturação de alumínio. Extrator: Norte-Carolina (duplo ácido). 
As leguminosas foram semeadas no campo experimental em 01/11/2003, a partir de sementes escarificadas mecanicamente, com o adicional de $50 \%$ na sua densidade, para assegurar o estande, exceto a gliricídia, que foi propagada a partir de estacas $(40 \mathrm{~cm} \mathrm{de}$ comprimento) enterradas em sulco de plantio. Depois de 30 dias da emergência das plântulas realizou-se o desbaste, mantendo-se duas por metro, para todas as espécies.

As leguminosas foram podadas manualmente, em 01/07/2004, oito meses após o plantio, a 1,5 m de altura e todas as folhas e ramos menores que $1,5 \mathrm{~cm}$ de diâmetro foram espalhados no solo e incorporados com grade niveladora (ALCÂNTARA et al., 2000; BARRETO \& FERNANDES, 2001). Os galhos mais grossos que $1,5 \mathrm{~cm}$ de diâmetro foram retirados da área para facilitar a incorporação da massa vegetal com a grade.

A semeadura do milho (híbrido intervarietal UENF 506-8) foi realizada duas semanas após a poda, em 15/07/ 2004. O desbaste foi realizado 30 dias após a emergência das plântulas (19/08/2004), deixando-se quatro por metro. A fase de pendoamento/embonecamento se iniciou aos 68 dias após a emergência (28/09/2004), época em que foram coletadas as folhas de milho para a análise de N, P e K.

No primeiro ciclo de cultivo do milho não ocorreu irrigação por vinte dias, na fase de pendoamento/ embonecamento, por causa da falta de água no lago de abastecimento. Nesse período não houve precipitações, o que gerou déficit hídrico para o milho.

Depois da colheita das espigas a área foi deixada em pousio por três meses e, a seguir, preparada com uma aração e uma gradagem para controle das plantas daninhas e incorporação dos restos culturais. Em 18/04/2005, as leguminosas foram novamente podadas a 1,5 m de altura, ficando somente a haste principal. Após a pesagem, a biomassa das leguminosas foi espalhada na área correspondente a sua parcela e incorporada ao solo por gradagem.

Após a segunda semeadura do milho (28/04/2005) foi feito o desbaste, manualmente, 30 dias após a emergência, deixando-se quatro plantas por metro, ocasião em que se fez a cobertura nitrogenada na testemunha adubada. A coleta de folhas para análise de N, P e K foi realizada em 15/07/05, na fase de "embonecamento" do milho.

Nos dois ciclos de cultivo, algumas operações foram realizadas em comum: irrigação por aspersão uniforme em todas as parcelas, uma vez por semana com lâmina de $20 \mathrm{~mm}$ e capinas manuais para controle das plantas daninhas até 30 dias após a emergência do milho. O manejo fitossanitário foi realizado para reduzir o ataque de lagarta do cartucho (Spodoptera frugiperda), por meio de duas aplicações de inseticida (delthametrina 25 CE na dose de $0,2 \mathrm{~L} \mathrm{ha}^{-1}$ ). A segunda poda das leguminosas foi realizada 60 dias após a emergência do milho. Nos dois ciclos, o material da primeira poda foi incorporado ao solo com gradagem e o da segunda, espalhado sobre o solo, sem incorporação.

Para determinação dos teores de N-orgânico, $\mathrm{P}$ e K foi tomada a folha oposta e abaixo da primeira espiga de plantas ao acaso, no período de aparecimento da inflorescência feminina (MALAVOLTA et al., 1997). Foi determinado o número de espigas/planta, a massa média de 1000 grãos de milho e a massa de grãos por parcela. A produtividade de grãos de milho $\left(\mathrm{kg} \mathrm{ha}^{-1}\right)$ foi obtida extrapolando-se a produção de grãos da área útil da parcela para um hectare (STORCK \& UITDEWILLIGEN, 1980), ponderando-se a perda de área ocupada pelas aléias. As massas de grãos foram corrigidas para $13 \%$ de umidade.

Foi utilizado o delineamento em blocos casualizados com quatro repetições. A fim de se detectar o efeito dos tratamentos, realizou-se a análise de variância. Em caso de efeitos significativos foi aplicado o teste de agrupamento de Scott-Knott, a 5\% de probabilidade.

\section{RESULTADOS E DISCUSSÃO}

Os dados de aporte de N, P e K pela fitomassa das leguminosas e respectivas produtividades são resumidos na Tabela 1. Esses resultados servirão para fundamentar as discussões acerca das características agronômicas avaliadas na cultura do milho em consórcio e não serão discutidos detalhadamente nesse trabalho.

Verificaram-se, nos tratamentos milho solteiro+NPK e milho+guandu, os maiores teores foliares de nitrogênio no primeiro ciclo de cultivo do milho (Tabela 2). Tal resultado evidencia que o maior aporte de $\mathrm{N}$ pela fitomassa dessa espécie (Tabela 1) contribuiu para a nutrição nitrogenada do milho, conforme observado por Heineman et al. (1997) e Rao \& Mathuva (2000). O teor foliar de N foi $22 \%$ superior no milho associado ao guandu em relação ao milho solteiro, sem aplicação de NPK.

No segundo ciclo de cultivo, todos os tratamentos foram similares e superaram o milho solteiro sem NPK, nos teores foliares de $\mathrm{N}$ e P (Tabela 2), possivelmente, pelo efeito acumulativo da aplicação de fitomassa e a provável maior decomposição. Heinrichs et al. (2002) relataram ausência de resposta às leguminosas nos teores foliares de macronutrientes no milho no primeiro ano de cultivo em sistema intercalar; entretanto, no segundo ano algumas leguminosas influenciaram o teor foliar de $\mathrm{N}$, provavelmente em função do maior aporte de biomassa. 
TABELA 1 - Produtividade de fitomassa seca (FMS) e aporte de N, P e K pela biomassa das leguminosas, por dois ciclos de cultivo, em Campos dos Goytacazes-RJ.

\begin{tabular}{|c|c|c|c|c|c|c|c|c|}
\hline \multirow{3}{*}{ Tratamento } & \multicolumn{4}{|c|}{ Primeiro ciclo } & \multicolumn{4}{|c|}{ Segundo ciclo } \\
\hline & FMS & $\mathbf{N}$ & $\mathbf{P}$ & $\mathbf{K}$ & FMS & $\mathbf{N}$ & $\mathbf{P}$ & $\mathbf{K}$ \\
\hline & \multicolumn{8}{|c|}{ kg ha } \\
\hline Guandu & $5371 \mathrm{a}$ & $114 \mathrm{a}$ & $9,7 \mathrm{a}$ & $48 \mathrm{a}$ & $4486 \mathrm{a}$ & $96 \mathrm{a}$ & $8,1 \mathrm{a}$ & $40 \mathrm{a}$ \\
\hline Canafístula & $1670 \mathrm{~b}$ & $34 \mathrm{c}$ & $2,7 \mathrm{c}$ & $12 \mathrm{c}$ & $3630 \mathrm{~b}$ & $73 \mathrm{~b}$ & $5,8 \mathrm{~b}$ & $25 \mathrm{~b}$ \\
\hline Leucena & $1613 \mathrm{c}$ & $52 \mathrm{~b}$ & $3,4 \mathrm{~b}$ & $19 \mathrm{~b}$ & $1464 \mathrm{~d}$ & $47 \mathrm{c}$ & $3,1 \mathrm{c}$ & $18 \mathrm{c}$ \\
\hline Sabiá & $1108 \mathrm{c}$ & $26 \mathrm{c}$ & $1,6 \mathrm{c}$ & $7 \mathrm{~d}$ & $1862 \mathrm{~d}$ & $43 \mathrm{c}$ & $2,8 \mathrm{~d}$ & $11 \mathrm{~d}$ \\
\hline Sesbânia & $1091 \mathrm{c}$ & $33 \mathrm{c}$ & $2,3 \mathrm{c}$ & $13 \mathrm{c}$ & $648 \mathrm{e}$ & $20 \mathrm{~d}$ & $1,4 \mathrm{~d}$ & $8 \mathrm{~d}$ \\
\hline Gliricídia & $360 \mathrm{~d}$ & $11 \mathrm{~d}$ & $0,6 \mathrm{~d}$ & $4 \mathrm{e}$ & $2386 \mathrm{c}$ & $75 \mathrm{~b}$ & $4,1 \mathrm{c}$ & $29 \mathrm{~b}$ \\
\hline Albízia & $193 \mathrm{~d}$ & $6 \mathrm{~d}$ & $0,3 \mathrm{~d}$ & $2 \mathrm{e}$ & $463 \mathrm{e}$ & $15 \mathrm{~d}$ & $0,7 \mathrm{~d}$ & $5 \mathrm{~d}$ \\
\hline C.V.: \% & 19 & 19 & 19 & 19 & 17 & 15 & 16 & 15 \\
\hline
\end{tabular}

Médias seguidas da mesma letra na coluna não diferem significativamente entre si pelo teste de agrupamento de ScottKnott a $5 \%$ de probabilidade.

TABELA 2 - Teores de nitrogênio, fósforo e potássio, nas folhas de milho cultivado em aléias com leguminosas, em Campos dos Goytacazes-RJ.

\begin{tabular}{|c|c|c|c|c|c|c|}
\hline \multirow{3}{*}{ Tratamento } & \multicolumn{3}{|c|}{ Primeiro ciclo } & \multicolumn{3}{|c|}{ Segundo ciclo } \\
\hline & $\mathbf{N}$ & $\mathbf{P}$ & $\mathbf{K}$ & $\mathbf{N}$ & $\mathbf{P}$ & $\mathbf{K}$ \\
\hline & \multicolumn{6}{|c|}{ Teor $\left(\mathrm{g} \mathrm{kg}^{-1}\right)$} \\
\hline Milho+guandu & $16,7 \mathrm{a}$ & $2,4 \mathrm{a}$ & $12,7 \mathrm{~b}$ & $20,4 \mathrm{a}$ & $2,4 \mathrm{a}$ & $16,9 \mathrm{a}$ \\
\hline Milho+canafístula & $13,8 \mathrm{~b}$ & $2,5 \mathrm{a}$ & $12,2 \mathrm{~b}$ & $19,8 \mathrm{a}$ & $2,4 \mathrm{a}$ & $15,8 \mathrm{a}$ \\
\hline Milho+leucena & $14,5 \mathrm{~b}$ & $2,2 \mathrm{a}$ & $13,8 \mathrm{~b}$ & $20,1 \mathrm{a}$ & $2,3 \mathrm{a}$ & $15,9 \mathrm{a}$ \\
\hline Milho+sabiá & $13,6 \mathrm{~b}$ & $2,1 \mathrm{a}$ & $12,2 \mathrm{~b}$ & $19,8 \mathrm{a}$ & $2,3 \mathrm{a}$ & $16,3 \mathrm{a}$ \\
\hline Milho+sesbânia & $13,6 \mathrm{~b}$ & $2,1 \mathrm{a}$ & $12,3 \mathrm{~b}$ & $17,5 \mathrm{a}$ & $2,3 \mathrm{a}$ & $16,4 \mathrm{a}$ \\
\hline Milho+gliricídia & $14,8 \mathrm{~b}$ & $2,3 \mathrm{a}$ & $13,2 \mathrm{~b}$ & $20,7 \mathrm{a}$ & $2,4 \mathrm{a}$ & $17,2 \mathrm{a}$ \\
\hline Milho+albízia & $13,9 \mathrm{~b}$ & $2,2 \mathrm{a}$ & $12,1 \mathrm{~b}$ & $18,7 \mathrm{a}$ & $2,3 \mathrm{a}$ & $16,3 \mathrm{a}$ \\
\hline M solteiro s/ NPK & $13,6 \mathrm{~b}$ & $2,0 \mathrm{a}$ & $12,7 \mathrm{~b}$ & $15,9 \mathrm{~b}$ & $1,9 \mathrm{~b}$ & $15,4 \mathrm{a}$ \\
\hline M solteiro+NPK & $18,6 \mathrm{a}$ & $2,6 \mathrm{a}$ & $15,8 \mathrm{a}$ & $24,7 \mathrm{a}$ & $2,8 \mathrm{a}$ & $17,0 \mathrm{a}$ \\
\hline Média & 14,9 & 2,2 & 12,9 & 19,7 & 2,3 & 16,3 \\
\hline C.V.: \% & 18,1 & 20,3 & 10,1 & 12,1 & 11,3 & 7,1 \\
\hline
\end{tabular}

Médias seguidas da mesma letra na coluna não diferem significativamente entre si pelo teste de agrupamento de ScottKnott a $5 \%$ de probabilidade.

Apesar dos valores diferenciados, o teor foliar de $\mathrm{N}$ em todos os tratamentos ficou abaixo da faixa adequada de 27,5 a 32,5 $\mathrm{g} \mathrm{kg}^{-1}$ para a cultura no milho, segundo Malavolta et al. (1997). No campo esse fato foi comprovado visualmente em todos os tratamentos, sendo observado amarelecimento da extremidade foliar para a base em forma de "V". Os teores foliares de P no milho ficaram dentro da faixa adequada em todos os tratamentos (1,9 a 3,5 $\left.\mathrm{g} \mathrm{kg}^{-1}\right)$, segundo Malavolta et al. (1997).

No primeiro ciclo não ocorreu efeito dos tratamentos sobre os teores foliares de P (Tabela 2), possivelmente, em função do baixo conteúdo de $\mathrm{P}$ na biomassa das leguminosas (Tabela 1). No segundo ciclo, todos os tratamentos se assemelharam e apresentaram teores superiores à testemunha sem adubação, possivelmente pela mineralização da fitomassa das leguminosas, associada à possibilidade da ação de micorrizas no consórcio. Heinrichs et al. (2002), também só encontraram diferenças entre os teores foliares de $\mathrm{P}$ no milho consorciado com leguminosas, no segundo ciclo de cultivo. Entretanto, esses autores realizaram a pesquisa num Nitossolo Eutrófico de alta fertilidade e todos os tratamentos receberam fertilizantes. 
No primeiro ciclo de cultivo, os teores foliares de $\mathrm{K}$ no milho não foram influenciados pelas leguminosas, sendo todos inferiores ao milho solteiro+NPK. Em função da restrição hídrica no primeiro ciclo, somente o fertilizante mineral altamente solúvel, foi capaz de possibilitar um maior teor foliar de K (Tabela 1). No segundo ciclo de cultivo, todos os tratamentos se igualaram à testemunha adubada. Entretanto, todos os tratamentos resultaram em teores foliares de $\mathrm{K}$ abaixo da faixa adequada (17,5 a 29,7 $\mathrm{g} \mathrm{kg}^{-1}$ ), segundo Malavolta et al. (1997).

As leguminosas e a adubação NPK não foram capazes de afetar positivamente o índice de espigas da cultura do milho nos dois ciclos de cultivo (Tabela 3 ). Barreto \& Carvalho Filho (1992), não observaram efeito da leucena nesse índice em três anos de ensaio e relataram valores relativamente baixos, entre 1,0 e 0,66 espigas por planta.

Observou-se no milho cultivado solteiro+NPK a maior média da massa de 1000 grãos no primeiro cultivo (Tabela 3). No segundo ciclo houve separação das médias em quatro grupos. O milho solteiro+NPK superou todos os tratamentos, no entanto, a aléia com gliricídia proporcionou grãos $15 \%$ mais pesados que a testemunha sem NPK. Demonstra-se, dessa forma, o efeito da fitomassa da gliricídia sobre a massa dos grãos, o que também foi observado por Heineman et al. (1997). Os tratamentos em que a aléia foi composta pelas outras espécies afetaram pouco a massa de 1000 grãos, mas, ainda assim, foram superiores ao obtido pelo milho solteiro sem adubação.
Possivelmente, com mais anos de cultivo e maior desenvolvimento de sistema radicular na área, essas espécies produzirão mais fitomassa. Assim, tais leguminosas merecem avaliação por mais tempo para se definir o potencial para uso em aléias com milho na região e a possível sustentabilidade desse sistema de produção. O milho solteiro sem NPK produziu as sementes mais leves, em função dos mais baixos teores foliares de N (Tabela 2), pois dependeu apenas da baixa disponibilidade de nutrientes do solo (Quadro 1), portanto, afetando negativamente a granação, que foi inadequada e gerou menor massa de grãos.

No primeiro ciclo de cultivo, o milho solteiro adubado superou todos os tratamentos na produtividade de grãos, não havendo diferença entre os demais tratamentos (Tabela 3). A adição da fitomassa das leguminosas no primeiro ciclo foi insuficiente para afetar o rendimento dos grãos, possivelmente, pela baixa mineralização dessa matéria orgânica, associado ao curto período experimental. Heinrichs et al. (2005), avaliando espécies de leguminosas em consórcio com milho, em Piracicaba-SP, observaram de forma semelhante, que, no primeiro ano de cultivo, o rendimento de grãos de milho não foi influenciado pelo cultivo intercalar com leguminosas.

Ocorreu grande aumento nos valores de todas as características fitotécnicas do milho avaliadas no segundo ciclo de cultivo (Tabelas 2 e 3 ), certamente pela deficiência hídrica ocorrida no período de florescimento da cultura do milho, no primeiro ciclo de cultivo.

TABELA 3-Número de espigas por planta (EPP), massa de 1000 grãos e produtividade de milho (PROD), cultivado em aléias com leguminosas, em Campos dos Goytacazes-RJ.

\begin{tabular}{lcccccc}
\hline \multicolumn{1}{c}{ Tratamentos } & EPP & \begin{tabular}{c} 
Primeiro ciclo \\
$\mathbf{1 0 0 0}$ grãos \\
\cline { 2 - 6 }
\end{tabular} & $\begin{array}{c}\text { PROD } \\
(\mathbf{g g ~ h a})\end{array}$ & EPP & $\begin{array}{c}\text { Segundo ciclo } \\
\mathbf{1 0 0 0} \text { grãos } \\
(\mathbf{g})\end{array}$ & $\begin{array}{c}\text { PROD } \\
(\mathbf{k g ~ h a})\end{array}$ \\
\hline Milho+guandu & $0,7 \mathrm{a}$ & $228 \mathrm{~b}$ & $1417 \mathrm{~b}$ & $1,0 \mathrm{a}$ & $306 \mathrm{c}$ & $5213 \mathrm{~b}$ \\
Milho+canafístula & $0,7 \mathrm{a}$ & $228 \mathrm{~b}$ & $1302 \mathrm{~b}$ & $1,0 \mathrm{a}$ & $301 \mathrm{c}$ & $4889 \mathrm{c}$ \\
Milho+leucena & $0,6 \mathrm{a}$ & $223 \mathrm{~b}$ & $1411 \mathrm{~b}$ & $1,0 \mathrm{a}$ & $291 \mathrm{c}$ & $4704 \mathrm{c}$ \\
Milho+sabiá & $0,7 \mathrm{a}$ & $215 \mathrm{~b}$ & $1302 \mathrm{~b}$ & $0,9 \mathrm{a}$ & $290 \mathrm{c}$ & $4175 \mathrm{c}$ \\
Milho+sesbânia & $0,8 \mathrm{a}$ & $205 \mathrm{~b}$ & $1357 \mathrm{~b}$ & $0,9 \mathrm{a}$ & $290 \mathrm{c}$ & $4152 \mathrm{c}$ \\
Milho+gliricídia & $0,7 \mathrm{a}$ & $229 \mathrm{~b}$ & $1366 \mathrm{~b}$ & $0,9 \mathrm{a}$ & $316 \mathrm{~b}$ & $5228 \mathrm{~b}$ \\
Milho+albízia & $0,7 \mathrm{a}$ & $216 \mathrm{~b}$ & $1218 \mathrm{~b}$ & $0,9 \mathrm{a}$ & $291 \mathrm{c}$ & $4428 \mathrm{c}$ \\
M solteiro s/ NPK & $0,6 \mathrm{a}$ & $200 \mathrm{~b}$ & $954 \mathrm{~b}$ & $0,9 \mathrm{a}$ & $276 \mathrm{~d}$ & $3476 \mathrm{~d}$ \\
M solteiro+NPK & $0,8 \mathrm{a}$ & $265 \mathrm{a}$ & $1767 \mathrm{a}$ & $1,0 \mathrm{a}$ & $327 \mathrm{a}$ & $6062 \mathrm{a}$ \\
\hline Média & 0,7 & 223 & 1344 & 0,9 & 299 & 4703 \\
C.V.: \% & 18,8 & 5,1 & 22,8 & 11,4 & 4,5 & 20,4 \\
\hline
\end{tabular}

Médias seguidas da mesma letra na coluna não diferem significativamente entre si pelo teste de agrupamento de ScottKnott, a $5 \%$ de probabilidade. 
No segundo ciclo, observou-se no milho solteiro+NPK produtividade superior a todos os tratamentos (Tabela 3). Entretanto, na testemunha sem NPK notou-se a menor produtividade de grãos. O solo distrófico (Quadro 1) e sem adubação não foi capaz de disponibilizar nutrientes suficientes para o milho e, portanto afetou negativamente a produtividade. $\mathrm{O}$ milho é uma cultura de ciclo curto, exigente em solo fértil e responsiva ao $\mathrm{N}$ (COELHO et al., 2002).

Por outro lado, nas aléias com guandu e com gliricídia, o milho atingiu em média produtividades 13,9\% inferiores ao milho adubado, mas proporcionando, acréscimo médio de $50 \%$ em relação ao milho sem NPK. Guandu e gliricídia foram capazes de aumentar o rendimento de grãos, sem o custo adicional da aquisição de fertilizantes químicos, que na maioria das vezes são onerosos para a agricultura familiar. Observa-se assim, o efeito positivo da fitomassa adicionada, que mineralizada fornece nutrientes. Esse resultado é corroborado pelo obtido por Heinrichs et al. (2005), relatando que a produtividade de milho foi beneficiada pelo consórcio, no segundo ciclo de cultivo.

Barreto \& Fernandes (2001), avaliando o efeito de gliricídia e leucena na produção de mandioca, relataram a interferência negativa da leucena, quando comparada à gliricídia. Mathuva et al. (1998) relataram produtividades 15 a $30 \%$ superiores no milho solteiro fertilizado em relação àquele consorciado com leucena. A gliricídia é uma espécie que favoreceu maiores produtividades, possivelmente pelo fato de ser pouco competitiva por nutrientes, luz e água. Também Lose et al. (2003) referem-se à gliricídia como uma espécie não competitiva em conseqüência do sistema radicular dessa espécie ser menos desenvolvido, mas com alta capacidade de rebrota após as podas. Por outro lado, Alves et al. (2004) concluíram que o sistema de cultivo de cenoura e beterraba em aléias de guandu, pode representar uma prática vantajosa por contribuir na manutenção da fertilidade do solo, podendo gerar receitas adicionais.

Nas aléias com canafístula e com leucena verificou-se o incremento da produtividade de milho em média $38 \%$ em relação à testemunha sem adubo, no segundo ciclo (Tabela 3). Além do benefício para a nutrição, espera-se com cultivos em aléias de leguminosas, a redução da erosão pela diminuição do impacto das chuvas, o aumento da infiltração, por causa da maior porosidade e conseqüente redução das enxurradas que provocam grandes perdas aos solos agrícolas (BARRETO \& FERNANDES, 2001; CARVALHO et al., 2004).

\section{CONCLUSÕES}

No primeiro ciclo de cultivo, dentre as aléias, somente a de guandu afetou positivamente o teor foliar de $\mathrm{N}$ no milho e a testemunha adubada proporcionou os maiores teores foliares de $\mathrm{N}$ e $\mathrm{K}$.

No segundo ciclo, a testemunha sem adubo foi inferior a todos os tratamentos, que se assemelharam nos teores foliares de $\mathrm{N}$ e P; e não houve efeito dos tratamentos sobre os teores foliares de $\mathrm{K}$.

Os efeitos positivos do guandu e da gliricídia na produtividade de grãos ocorreram no segundo ciclo de cultivo em consórcio.

\section{REFERÊNCIAS BIBLIOGRÁFICAS}

ALCÂNTARA, F. A. de; FURTINI NETO, A. E.; PAULA, M. B. de; MESQUITA, H. A. de; MUNIZ, J. A. Adubação verde na recuperação da fertilidade de um latossolo vermelho-escuro degradado. Pesquisa Agropecuária Brasileira, Brasília, v. 35, p. 277-288, 2000.

ALTIERI, M. A. Agroecology: the science of natural resource management for poor farmers in marginal environments. Agriculture, Ecosystems and Environment, Amsterdam, v. 93, p. 1-24, 2002.

ALVES, S. M. C.; ABBOUD, A. C. de S.; RIBEIRO, R. de L. D.; ALMEIDA, D. J. Balanço do nitrogênio e fósforo em solo com cultivo orgânico de hortaliças após incorporação de biomassa de guandu. Pesquisa Agropecuária Brasileira, Brasília, v. 39, p. 1111-1117, 2004.

BARRETO, A. C.; CARVALHO FILHO, O. M. Cultivo de leucena em consórcio de leucena com feijão, milho e algodão. Pesquisa Agropecuária Brasileira, Brasília, v. 27, p. 1533-1540, 1992.

BARRETO, A. C.; FERNANDES, M. F. Cultivo de Gliricidia sepium e Leucaena leucocephala em alamedas visando a melhoria dos solos dos tabuleiros costeiros. Pesquisa Agropecuária Brasileira, Brasília, v. 36, p. 1287 1293, 2001.

CARVALHO, R.; GOEDERT, W. J.; ARMANDO, M. S. Atributos físicos da qualidade de um solo sob sistema agroflorestal. Pesquisa Agropecuária Brasileira, Brasília, v. 39, p. 1153-1155, 2004. 
COELHO, A. M.; FRANÇA, G. E.; PITTA, G. V. E.; ALVES, V. M. C.; HERNANI, L. C. Cultivo do milho nutrição e adubação. Sete Lagoas: Embrapa, 2002. 12 p. (Comunicado técnico, 44).

CONAB. Milho total $1^{\text {a }}$ e $\mathbf{2}^{\text {a }}$ safra: Brasil série histórica de produtividade: safras 1976/1977 a 2005/2006. Disponível em: <http://www.conab.gov.br/download/safra/ milhototalseriehist.xls> Acesso em: 4 jun. 2006.

HEINEMAN, A. M.; OTIENO, H. J. O.; MENGICH, E. K.; AMADALO, A. Growth and yield of eight agroforestry tree species in line plantings in Western Kenya and their effect on maize yields and soil properties. Forest Ecology and Management, Amsterdam, v. 91, p. 103-135, 1997.

HEINRICHS, R.; VITTI, G. C.; MOREIRA, A.; FANCELLI, A. L. Produção e estado nutricional do milho em cultivo intercalar com adubos verdes. Revista Brasileira de Ciência do Solo, Campinas, v. 26, p. 225-230, 2002.

HEINRICHS, R.; VITTI, G. C.; MOREIRA, A.; FIGUEIREDO, P. A.; FANCELLI, A. L.; CORAZZA, E. J. Características químicas de solo e rendimento de fitomassa de adubos verdes e de grãos de milho, decorrente do cultivo consorciado. Revista Brasileira de Ciência do Solo, Campinas, v. 29, p. 71-79, 2005.

LOSE, S. J.; HILGER, T. H.; LEIHNER, D. E.; KROSCHEL, J. Cassava, maize and tree root development as affected by various agroforestry and cropping systems in Bénin, West Africa. Agriculture, Ecosystems and Environment, Amsterdam, v. 100, p. 137-151, 2003.
MALAVOLTA, E.; VITTI, G. C.; OLIVEIRA, S. A. Avaliação do estado nutricional das plantas; princípios e aplicações. Piracicaba: Associação Brasileira para Pesquisa da Potassa e do Fosfato, 1997. 319 p.

MATHUVA, M. N.; RAO, M. R.; SMITHSON, P. C.; COE, $\mathrm{R}$. Improving maize (Zea mays) yields in semiarid highlands of Kenya: agroforestry or inorganic fertilizers? Field Crops Research, Amsterdam, v. 55, p. 57-72, 1998.

POLLI, H. de. (Coord.). Manual de adubação para o Rio de Janeiro. Itaguaí: Universidade Rural, 1988. 179 p.

RAO, M. R.; MATHUVA, M. N. Legumes for improving maize yields and income in semi-arid Kenya. Agriculture, Ecosystems and Environment, Amsterdam, v. 78, p. 123137, 2000.

RIBASKI, J.; MONTOYA, L. J.; RODIGHERI, H. R. Sistemas agroflorestais: aspectos ambientais e socioeconômicos. Informe Agropecuário, Belo Horizonte, v. 22, p. 61-67, 2001.

STAMFORD, N. P.; ORTEGA, A. D.; TEMPRANO, F.; SANTOS, D. R. Effects of phosphorus fertilization and inoculation of Bradyrhizobium and mycorrhizal fungi on growth of Mimosa caesalpiniaefolia in an acid soil. Soil Biology \& Biochemistry, Elmsford, v. 29, p. 959-964, 1997.

STORCK, L.; UITDEWILLIGEN, W. P. M. Estimativa para tamanho e forma de parcela e número de repetições para experimentos com milho (Zea mays L.). Agronomia Sulriograndense, Porto Alegre, v. 16, n. 2, p. 269-182, 1980. 